\title{
Effect of N-Acetylcysteine on the treatment of acute respiratory distress syndrome in mechanically ventilated patients admitted to the intensive care unit
}

\author{
Mojtaba Ghorbi ${ }^{1}$, Mahbobe Rashidi $^{1} * \mathbb{D}$, Alireza Olapour $^{1}$, Fatemeh Javaherforooshzadeh ${ }^{1}$, Reza Akhondzadeh $^{1}$ \\ Received: 20 Nov 2020 \\ Published: 7 Jul 2021
}

\begin{abstract}
Background: N-acetylcysteine (NAC) is an antioxidant derived from the amino acid cysteine and is one of the drugs used in the treatment of respiratory diseases. The aim of this study was to investigate the effect of NAC on the treatment of acute respiratory distress syndrome in mechanically ventilated patients admitted to the intensive care unit.

Methods: This study was a randomized clinical trial. Patients under mechanical ventilation admitted to the intensive care unit were examined. Patients in the intervention group received daily $150 \mathrm{mg} / \mathrm{kg}$ of NAC on the first day of admiission and then $50 \mathrm{mg} / \mathrm{kg}$ up to the fourth day of admission. Patients in the control group received routine care. The vital signs, level of consciousness, and other important variables were recorded. Data were analyzed using statistical tests and SPSS software version 24.

Results: There was no significant difference between MAP, heart rate, respiratory rate, $\mathrm{O}_{2}$ Sat, APACHE II score, and pulmonary capacity of the patients in the two groups on the first, second, third and fourth days after the intervention ( $>0.05$ ). There was no significant difference between the level of consciousness (according to GCS criteria), respiratory index $\left(\mathrm{PAO}_{2} / \mathrm{FIO}_{2}\right)$ and PEEP of patients in the two study groups within 1 to 2 days after the intervention ( $>>0.05)$. There was a significant difference between the level of consciousness (based on GCS criteria), respiratory index $\left(\mathrm{PAO}_{2} / \mathrm{FIO}_{2}\right)$ and PEEP of patients in the two study groups within 3 to 4 days after the intervention $(\mathrm{p}<0.05)$. There was no significant difference between the duration of hospitalization in the ICU, the time required for mechanical ventilation and the mortality rate of the patients in the two groups $(\mathrm{p}>0.05)$.

Conclusion: It seems that $\mathrm{N}$-acetylcysteine has a positive effect on the treatment of acute respiratory distress syndrome in mechanically ventilated patients admitted to the intensive care unit.
\end{abstract}

Keywords: N-acetylcysteine, Acute respiratory distress syndrome, Mechanical ventilation, Intensive care

Conflicts of Interest: None declared

Funding: This research has been financially supported by Pain Research Center of Ahvaz University of Medical Sciences, Ahvaz, Iran ('grant No: 9814).

*This work has been published under CC BY-NC-SA 1.0 license.

Copyright $\subseteq$ Iran University of Medical Sciences

Cite this article as: Ghorbi M, Rashidi M, Olapour A, Javaherforooshzadeh F, Akhondzadeh R. Effect of N-Acetylcysteine on the treatment of acute respiratory distress syndrome in mechanically ventilated patients admitted to the intensive care unit. Med J Islam Repub Iran. 2021 (7 Jul);35:87. https://doi.org/10.47176/mjiri.35.87

\section{Introduction}

$\mathrm{N}$-acetylcysteine (NAC) is generally introduced as an antidote to acetaminophen poisoning; however, it has a variety of other clinical applications that are supported by scientific evidence. The sulfhydryl acetylcysteine group breaks the disulfide bonds of the concentrated secretions of the bronchial system, which results in the formation of lighter molecules that facilitate the flow of sputum and are

Corresponding author: Dr Mahbobe Rashidi, rashidi-m@ajums.ac.ir

Department of Anesthesia, Ahvaz Anesthesiology and Pain Research Center, Ahvaz Jundishapur University of Medical Sciences, Ahvaz, Iran expelled by coughing. $\mathrm{T}$ herefore, it reduces the risk of infectious diseases in the respiratory tract. Moreover, by clearing the airways, the cough is relieved and it becomes easier to breathe $(1,2)$.

The clinical functions stem from its capability to protect the antioxidant and nitric oxide organizations of the body through stress, infections, toxic injuries, and inflammatory

$\uparrow$ What is "already known" in this topic:

To control oxidative lung impairments it can be used the NACat the lowest intracellular concentration.

$\rightarrow$ What this article adds:

Based on the results, it seems that NAC is an effective medication with low side effects for the treatment of ARDS in mechanically ventilated patients admitted to the ICU. 
circumstances. Treatment with NAC supplementation appears to increase glutathione which is the main antioxidant of the body. In addition, it decreases the construction of anti-inflammatory cytokines, for instance, interleukin- 8 and tumor necrosis factor-alpha (3).

Acute respiratory distress syndrome (ARDS) is manifested as rapidly progressing shortness of breath, tachypnea, and hypoxemia. Its diagnostic standards contain acute onset, severe hypoxemia, bilateral pulmonary infiltration, and lack of left atrial hypertension. The ARDS occurs when a pulmonary or extrapulmonary injury triggers the discharge of inflammatory intermediaries and thereby stimulates the neutrophil accumulation in the pulmonary microcirculation. Neutrophils impair the vascular endothelium and alveolar epithelium, which leads to pulmonary edema, hyaline coating creation, reduced lung compliance, and difficulty in air replacement (4-6).

The ARDS survivors often suffer from significant physical and mental disabilities, which lead to increased medical costs and the need to use social health care (7). In the last decade, several methods have been proposed for the treatment of ARDS, such as improvement of fluid management, non-invasive mechanical ventilation solutions, and ventilation management $(8,9)$.

The annual mortality rate of ARDS in hospitals has declined to some extent in recent years; however, it still imposes a heavy social burden and high healthcare costs (10, 11). Most cases of ARDS are related to pneumonia or septicemia. It is expected that $7.1 \%$ of all individuals hospitalized in the intensive care unit and $16.1 \%$ of all individuals who use mechanical ventilation suffer from acute lung injury (ALI) or ARDS (12).

Handling of ARDS requires supportive care, including automated aeration, inhibition of ulcer stress and venous thromboembolism, and nutritional care . Most ARDS patients require sedation, intubation, and ventilation at the same time as the treatment of the underlying disease (13). Medication choices for the healing of ARDS are inadequate. Surfactant care may be supportive in pediatrics with ARDS; however, based on a Cochrane evaluation, it has no benefit for adults. Consumption of corticosteroids is debatable ; nevertheless, randomized controlled trials and cohort studies propose the initial usage of corticosteroids to reduce the duration of treatment with a ventilator (1416).

An important fact in the pathogenesis of ARDS is the oxidative damage to the lungs, which leads to the activation of the inflammatory system in the body. Glutathione (GSH/GSSG) is one of the most important and abundant antioxidants in the lungs that is reduced in inflammatory situations, including ARDS/ALI. Therefore, one approach to regulate oxidative lung damage is to reestablish the oxidant/antioxidant stability using the increasing intracellular glutathione statin using its precursors, like NAC, of the three amino acids that comprise glutathione (i.e., glutamate, glycine, and cysteine); cysteine has the lowest intracellular concentration. Since glutathione is mainly replaced by reproduction, the presence of cysteine can limit glutathione production during oxidative stress. The NAC can improve inflammation in various diseases, in- cluding chronic obstructive pulmonary illness, influenza, and idiopathic pulmonary fibrosis, by correction or prevention of severe glutathione deficiency (3).

The authors hypothesized that N-acetylcysteine improves oxygenation in mechanically ventilated patients and leads to increase respiratory index. So, this study was designed to investigate the effect of $\mathrm{N}$-acetylcysteine on the treatment of acute respiratory distress syndrome in mechanically ventilated individuals admitted to the intensive care unit of Imam Khomeini Hospital in Ahvaz in 2020 .

\section{Methods}

Study design

This study was a randomized clinical trial (IRCT20200425047201N1). The study population consisted of mechanically ventilated patients admitted to the intensive care unit (ICU) of Imam Khomeini Hospital in Ahvaz, Iran, in 2020.

\section{Ethical assessment}

This research was permitted by the Ethics Committee of Ahvaz University of Medical Sciences, Ahvaz, with the reference number: IR.IJUMS.REC.1398.389. This study was also based on the Declaration of Helsinki. Additionally, all participants were given written informed consent to complete questionnaires and were told that patients' data would be kept confidential. The participants were not paid to complete the questionnaires.

\section{Sampling and sample size calculation method}

The sample size was calculated after consultation with a professor of statistics and using the following formula with a significant level and measurement accuracy of 0.05 and 0.05 , respectively. Finally, the sample size was calculated at 58 subjects which was increased to 60 in order to increase the measurement accuracy.

$$
\mathrm{n}=\frac{\left(\mathrm{Z}_{1-\frac{\alpha}{2}}+\mathrm{Z}_{1-\beta}\right)^{2}\left(\delta_{1}^{2}+\delta_{2}^{2}\right)}{\left(\mu_{1}-\mu_{2}\right)^{2}}
$$

\section{Data collection method}

The proposal was approved by the ethics committee of Ahvaz University of Medical Sciences, and the required permissions were obtained from them. Afterward, the purpose of the study was explained to the participants and they were ensured of the confidentiality of information. Subsequently, written informed consent was obtained from all of the subjects. The participants consisted of eligible patients who were admitted to the ICU of Imam Khomeini Hospital in Ahvaz.

The inclusion criteria were 1) age range of 18-60 years, 2) mechanical ventilation for more than $48 \mathrm{~h}, 3$ ) respiratory index $\left(\mathrm{PAO}_{2} / \mathrm{FIO}_{2}\right) \leq 200 \mathrm{mmHg}$, 4) positive endexpiratory pressure (PEEP) $\geq 10 \mathrm{~cm} \mathrm{H}_{2} \mathrm{O}$, and 5) bilateral pulmonary infiltration based on a chest $\mathrm{x}$-ray.

On the other hand, the exclusion criteria consisted of 1) unwillingness, 2) cardiopulmonary diseases, such as con- 
gestive heart failure and pulmonary hypertension, 3) viral diseases, such as AIDS, hepatitis, and pulmonary tuberculosis, 4) history of chemotherapy or use of immunosuppressive medications during the last 3 months, 5) history of organ transplantation over the past 2 years, 6) confirmed brain death, and 7) possibility of NAC sensitivity.

In total, 60 eligible patients were included in the research and were randomly assigned into two equal groups. Randomization was performed by a simple incidental approach; after identifying eligible patents, they were arbitrarily allocated a three-digit proprietary code by using a random table. The last digit on the right determines patient collection. If the figure is $0,1,2,3,4$ it was placed in the intervention group (NAC) and if the figure is 5, 6, 7, 8, 9 it was placed in the control group. Double blinding was also performed; person in charge of care and data analyzer were not aware of the distribution of collections. In addition to routine care, the intervention group received 150 and $50 \mathrm{mg} / \mathrm{kg}$ NAC intravenously on day 1 and days 2-4 of hospitalization, respectively. The patients in the control group only received routine care.

In addition to the vital signs and level of consciousness of the patients, their respiratory index $\left(\mathrm{PAO}_{2} / \mathrm{FIO}_{2}\right)$, required PEEP for effective mechanical ventilation, APACHE II score, length of stay in ICU, the required duration of mechanical ventilation, mortality rate, and the pulmonary capacity of patients in both groups were studied and recorded during a 4-day period.

\section{Data analysis}

The results were expressed for quantitative variables as mean and standard deviation (Mean \pm SD) and for qualitative variables as percentage. First, the normality of quantitative variables was assessed based on the KolmogorovSmirnov test and was not confirmed. Therefore, to compare quantitative variables in two groups, $t$ _ independent or U_ Mann-Whitney tests were used and to compare qualitative variables in two groups, the chi-square or Fisher exact tests were used. Also, to compare quantitative variables in days 1-4 after the intervention, the Repeated Measure ANOVA test was used.

Data were analyzed using SPSS software version 24. The significance level was considered to be less than 0.05 .

\section{Results}

In total, 60 eligible patients: under mechanical ventilation who were admitted to the ICU of Imam Khomeini Hospital in Ahvaz in 2009-2010 were included in this research project. A number of 30 patients $(50 \%)$ received $\mathrm{NAC}$, while the rest of the patients $(50 \%)$ received a placebo (Fig. 1).

There was no significant difference between the age and gender of the two groups ( $\mathrm{p}>0.05)$ (Table 1$)$.

Based on the results of the comparison between the groups indicated that there was no significant difference between the heart rate, respiratory rate, oxygen saturation, APACHE II score and pulmonary capacity of the two groups in 1-4 days after the intervention $(\mathrm{p}>0.05)$.

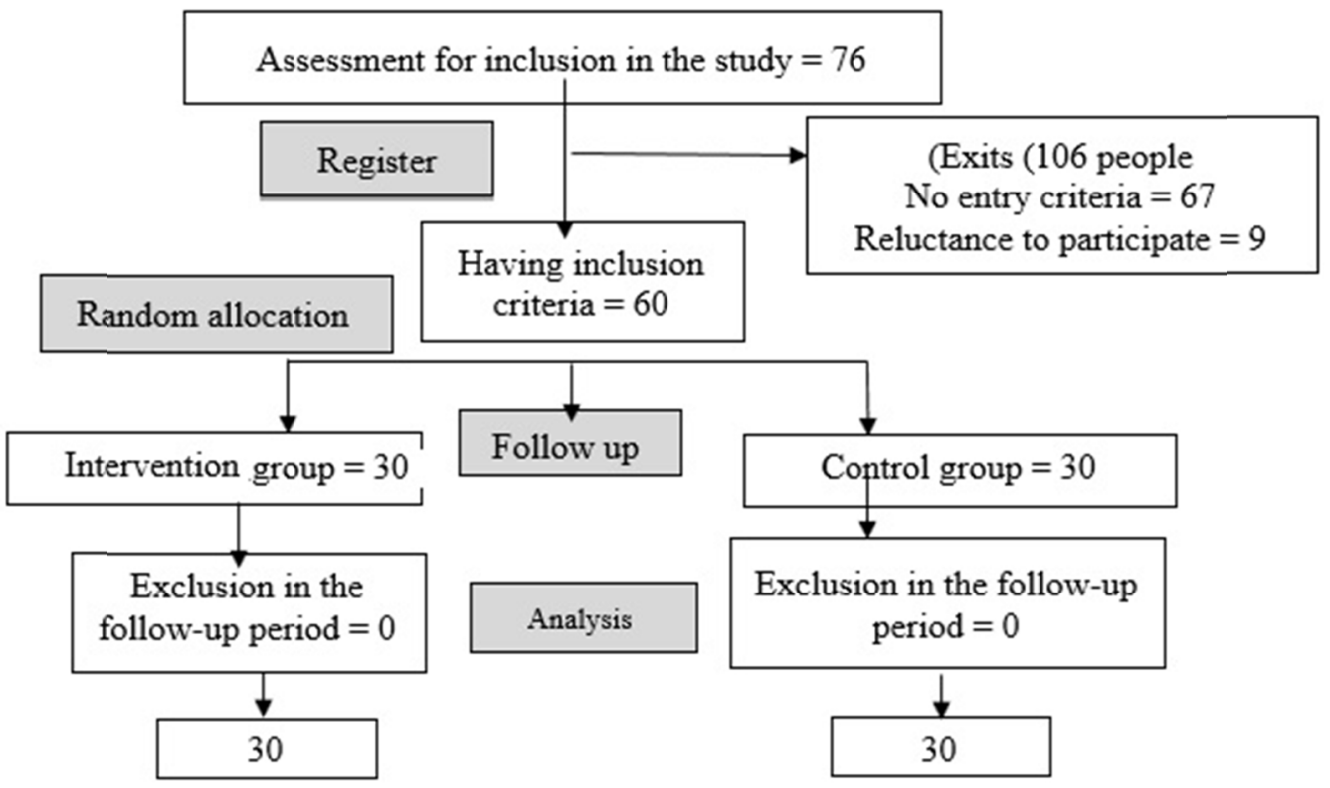

Fig. 1. Consort Flowchart

Table 1. Comparison of age and sex of patients in intervention and control group

\begin{tabular}{lccc}
\hline Variable & \multicolumn{2}{c}{ Group } & $\mathrm{p}$ \\
\cline { 2 - 4 } & Intervention & Control & 0.365 \\
Age (Mean \pm SD) & $43.73 \pm 16.88$ & $46.85 \pm 14.94$ & \\
Sex & & & 0.195 \\
Male & $19(63.3 \%)$ & $13(43.3 \%)$ & \\
\hline
\end{tabular}


There was no significant difference between the mean arterial blood pressure of the two groups on the days 1-3 after the intervention $(p>0.05)$. There was a significant difference between the mean arterial blood pressure of the two groups on the fourth day after the intervention $(\mathrm{p}<0.05)$.

There was no significant difference between the level of consciousness, Respiratory index $\left(\mathrm{PAO}_{2} / \mathrm{FIO}_{2}\right)$, and PEEP level of the two groups on the days 1-2 after the intervention ( $\mathrm{p}>0.05)$. There was no significant difference between the level of consciousness, Respiratory index $\left(\mathrm{PAO}_{2} / \mathrm{FIO}_{2}\right)$ and PEEP level of the two groups on the days 3-4 after the intervention $(\mathrm{p}>0.05)$.

Based on the results of the intergroup comparison, there was no significant difference between the mean arterial blood pressure, respiratory rate, oxygen saturation and APACHE II score of patients during 1-4 days after the intervention in the intervention group ( $p>0.05)$.

There was a significant difference between the heart rate, level of consciousness, respiratory index $\left(\mathrm{PAO}_{2} / \mathrm{FIO}_{2}\right)$, PEEP level and pulmonary capacity of patients during 1-4 days after the intervention in the intervention group $(\mathrm{p}<0.05)$.

There was no significant difference between the mean arterial blood pressure, respiratory rate, oxygen saturation, level of consciousness, PEEP level, and APACHE II score of patients during 1-4 days after the intervention in the control group ( $\mathrm{p}>0.05)$.

There was a significant difference between the heart rate, respiratory index $\left(\mathrm{PAO}_{2} / \mathrm{FIO}_{2}\right)$ and pulmonary capacity of patients during 1-4 days after the intervention in the control group $(\mathrm{p}<0.05)$ (Table 2$)$.

Based on the Bonferroni test, there was a significant difference between the level of consciousness between to group on the day $4 \quad(\mathrm{p}<0.05)$, Respiratory index $\left(\mathrm{PAO}_{2} / \mathrm{FIO}_{2}\right)$ and PEEP level of the two groups on days $1-4$ and 4 , after the intervention, respectively $(p<0.05)$. There was no significant difference between other variables in the two groups ( $>>0.05$ ) (Table 2).

Based on the results of the repeated measurement test (Table 3), for heart rate, only the time variable was significant. Because the interaction between time and group was not significant, it cannot be concluded that there was a significant difference between the two groups at different times. Considering oxygen saturation and pulmonary capacity variables, only the time variable was significant, indicating changes in time, but there was no significant difference between the two groups. In the level of consciousness and respiratory index $\left(\mathrm{PAO}_{2} / \mathrm{FIO}_{2}\right)$, both interaction and effect of group and time were significant

Table 2. Comparison of mean arterial blood pressure, heart rate, respiratory rate, oxygen saturation, level of consciousness, Respiratory index $\left(\mathrm{PAO}_{2} / \mathrm{FIO}_{2}\right)$, PEEP level, APACHE II score, and pulmonary capacity in intervention and control group during 1-4 days after the intervention

\begin{tabular}{|c|c|c|c|c|}
\hline \multirow[t]{2}{*}{ Variable } & \multirow{2}{*}{$\begin{array}{c}\text { Time } \\
\text { Measurement }\end{array}$} & \multicolumn{2}{|c|}{ Group } & \multirow[t]{2}{*}{$\bar{p}$} \\
\hline & & Intervention & Control & \\
\hline Mean arterial blood & 1 Day & $78.83 \pm 13.91$ & $83.2 \pm 11.4$ & 0.189 \\
\hline \multirow{3}{*}{ pressure } & 2 Day & $80.4 \pm 9.62$ & $84.06 \pm 9.62$ & 0.146 \\
\hline & 3 Day & $82.86 \pm 8.98$ & $86.7 \pm 9.59$ & 0.116 \\
\hline & 4 Day & $84.76 \pm 10.19$ & $85.93 \pm 9.44$ & 0.647 \\
\hline \multirow[t]{4}{*}{ Heart Rate } & 1 Day & $72.5 \pm 5.99$ & $76.96 \pm 10.79$ & 0.052 \\
\hline & 2 Day & $72.06 \pm 10.62$ & $71.3 \pm 12.72$ & 0.801 \\
\hline & 3 Day & $70.06 \pm 8.92$ & $72.43 \pm 12.29$ & 0.397 \\
\hline & 4 Day & $69.4 \pm 7.29$ & $70.8 \pm 9.28$ & 0.519 \\
\hline \multirow[t]{4}{*}{ Respiratory rate } & 1 Day & $17.76 \pm 1.56$ & $17.43 \pm 1.67$ & 0.430 \\
\hline & 2 Day & $17.63 \pm 2.35$ & $17.43 \pm 1.67$ & 0.945 \\
\hline & 3 Day & $70.06 \pm 8.92$ & $72.43 \pm 12.29$ & 0.422 \\
\hline & 4 Day & $69.4 \pm 7.29$ & $70.8 \pm 9.28$ & 0.193 \\
\hline \multirow[t]{4}{*}{ Oxygen saturation } & 1 Day & $92.33 \pm 3.64$ & $92.8 \pm 3.6$ & 0.620 \\
\hline & 2 Day & $94.3 \pm 2.87$ & $94.1 \pm 2.61$ & 0.779 \\
\hline & 3 Day & $94.03 \pm 3.13$ & $93.4 \pm 4.06$ & 0.502 \\
\hline & 4 Day & $94.5 \pm 2.22$ & $93.7 \pm 2.98$ & 0.244 \\
\hline \multirow[t]{4}{*}{ Level of consciousness } & 1 Day & $6.96 \pm 0.18$ & $6.96 \pm 0.31$ & 1.000 \\
\hline & 2 Day & $7.03 \pm 0.18$ & $7.1 \pm 0.4$ & 0.412 \\
\hline & 3 Day & $7.46 \pm 0.68$ & $7.16 \pm 0.59$ & 0.074 \\
\hline & 4 Day & $7.7 \pm 0.79$ & $7.13 \pm 0.43$ & 0.001 \\
\hline Respiratory index & 1 Day & $123.66 \pm 7.39$ & $123.8 \pm 7.04$ & 0.943 \\
\hline \multirow[t]{3}{*}{$\left(\mathrm{PAO}_{2} / \mathrm{FIO}_{2}\right)$} & 2 Day & $125.3 \pm 2.87$ & $125.8 \pm 3.95$ & 0.860 \\
\hline & 3 Day & $129.1 \pm 9.13$ & $124.63 \pm 5.41$ & 0.025 \\
\hline & 4 Day & $130.96 \pm 4.74$ & $127.6 \pm 2.4$ & 0.001 \\
\hline \multirow[t]{4}{*}{ PEEP level } & 1 Day & $4.56 \pm 0.67$ & $4.43 \pm 0.67$ & 0.450 \\
\hline & 2 Day & $4.66 \pm 0.71$ & $4.43 \pm 0.81$ & 0.243 \\
\hline & 3 Day & $4.76 \pm 0.56$ & $4.46 \pm 0.62$ & 0.057 \\
\hline & 4 Day & $4.96 \pm 0.18$ & $4.56 \pm 0.62$ & 0.001 \\
\hline \multirow[t]{4}{*}{ APACHE II score } & 1 Day & $13.63 \pm 2.42$ & $14.16 \pm 0.79$ & 0.257 \\
\hline & 2 Day & $14.16 \pm 2.3$ & $14.56 \pm 0.62$ & 0.363 \\
\hline & 3 Day & $14.16 \pm 0.53$ & $14.1 \pm 0.95$ & 0.740 \\
\hline & 4 Day & $14.43 \pm 1.22$ & $14.5 \pm 0.82$ & 0.805 \\
\hline \multirow[t]{4}{*}{ Pulmonary capacity } & 1 Day & $43.9 \pm 1.95$ & $43.5 \pm 2.37$ & 0.479 \\
\hline & 2 Day & $46.16 \pm 1.59$ & $45.7 \pm 1.87$ & 0.304 \\
\hline & 3 Day & $45.66 \pm 1.47$ & $44.76 \pm 3.3$ & 0.179 \\
\hline & 4 Day & $45.3 \pm 3.66$ & $44.83 \pm 3.22$ & 0.603 \\
\hline
\end{tabular}


Table 3. Repeated measurement for comparison of mean arterial blood pressure, heart rate, respiratory rate, oxygen saturation, level of consciousness, Respiratory index $\left(\mathrm{PAO}_{2} / \mathrm{FIO}_{2}\right)$, PEEP level, APACHE II score, and pulmonary capacity in intervention and control group during 1-4 days after the intervention

\begin{tabular}{|c|c|c|c|c|c|c|c|}
\hline Variable & Time.k & $\begin{array}{c}\text { Type IV Sum of } \\
\text { Squares }\end{array}$ & $\mathrm{df}$ & Mean Square & $\bar{F}$ & $\mathrm{p}$ & $\begin{array}{c}\text { Partial Eta } \\
\text { Squared } \\
\end{array}$ \\
\hline \multirow{5}{*}{$\begin{array}{l}\text { Mean arterial blood } \\
\text { pressure }\end{array}$} & time.k & 725.408 & 1 & 725.408 & 7.830 & 0.007 & 0.119 \\
\hline & $\begin{array}{l}\text { time.k * } \\
\text { Group }\end{array}$ & 66.741 & 1 & 66.741 & 0.720 & 0.399 & 0.012 \\
\hline & Error (time.k) & 5373.302 & 58 & 92.643 & & & \\
\hline & Group & 637.004 & 1 & 637.004 & 2.280 & 0.137 & 0.038 \\
\hline & Error & 16206.542 & 58 & 279.423 & & & \\
\hline \multirow[t]{5}{*}{ Heart Rate } & time.k & 616.333 & 1 & 616.333 & 21.927 & $<.001$ & 0.274 \\
\hline & $\begin{array}{l}\text { time.k * } \\
\text { Group }\end{array}$ & 27.603 & 1 & 27.603 & 0.982 & .326 & 0.017 \\
\hline & Error (time.k) & 1630.263 & 58 & 28.108 & & & \\
\hline & Group & 209.067 & 1 & 209.067 & 0.677 & 0.414 & 0.012 \\
\hline & Error & 17922.117 & 58 & 309.002 & & & \\
\hline \multirow{5}{*}{ Respiratory rate } & time.k & 2.168 & 1 & 2.168 & 0.699 & 0.407 & 0.012 \\
\hline & $\begin{array}{l}\text { time.k * } \\
\text { Group }\end{array}$ & 1.021 & 1 & 1.021 & 0.329 & 0.568 & 0.006 \\
\hline & Error (time.k) & 179.962 & 58 & 3.103 & & & \\
\hline & Group & 5.704 & 1 & 5.704 & 2.116 & 0.151 & 0.035 \\
\hline & Error & 156.342 & 58 & 2.696 & & & \\
\hline \multirow{5}{*}{ Oxygen saturation } & time.k & 50.841 & 1 & 50.841 & 4.673 & 0.035 & 0.075 \\
\hline & $\begin{array}{c}\text { time.k * } \\
\text { Group }\end{array}$ & 13.441 & 1 & 13.441 & 1.235 & 0.271 & 0.021 \\
\hline & Error (time.k) & 631.068 & 58 & 10.880 & & & \\
\hline & Group & 5.104 & 1 & 5.104 & 0.398 & 0.531 & 0.007 \\
\hline & Error & 743.542 & 58 & 12.820 & & & \\
\hline \multirow{5}{*}{$\begin{array}{l}\text { Level of conscious- } \\
\text { ness }\end{array}$} & time.k & 7.680 & 1 & 7.680 & 33.703 & $<0.001$ & 0.368 \\
\hline & $\begin{array}{c}\text { time.k * } \\
\text { Group }\end{array}$ & 3.203 & 1 & 3.203 & 14.058 & $<0.001$ & 0.195 \\
\hline & Error (time.k) & 13.217 & 58 & .228 & & & \\
\hline & Group & 2.400 & 1 & 2.400 & 6.247 & 0.015 & 0.097 \\
\hline & Error & 22.283 & 58 & .384 & & & \\
\hline \multirow{5}{*}{$\begin{array}{l}\text { Respiratory index } \\
\left(\mathrm{PAO}_{2} / \mathrm{FIO}_{2}\right)\end{array}$} & time.k & 986.453 & 1 & 986.453 & 31.749 & $<0.001$ & 0.354 \\
\hline & $\begin{array}{c}\text { time.k } * \\
\text { Group }\end{array}$ & 171.763 & 1 & 171.763 & 5.528 & 0.022 & 0.087 \\
\hline & Error (time.k) & 1802.083 & 58 & 31.070 & & & \\
\hline & Group & 212.817 & 1 & 212.817 & 4.889 & 0.031 & 0.078 \\
\hline & Error & 2524.617 & 58 & 43.528 & & & \\
\hline \multirow[t]{5}{*}{ PEEP level } & time.k & 2.253 & 1 & 2.253 & 7.188 & 0.010 & 0.110 \\
\hline & $\begin{array}{l}\text { time.k * } \\
\text { Group }\end{array}$ & .563 & 1 & .563 & 1.797 & 0.185 & 0.030 \\
\hline & Error (time.k) & 18.183 & 58 & .314 & & & \\
\hline & Group & 4.267 & 1 & 4.267 & 6.200 & 0.016 & \\
\hline & Error & 39.917 & 58 & .688 & & & \\
\hline \multirow[t]{5}{*}{ APACHE II score } & time.k & 6.453 & 1 & 6.453 & 2.698 & 0.106 & 0.044 \\
\hline & $\begin{array}{c}\text { time.k * } \\
\text { Group }\end{array}$ & 2.613 & 1 & 2.613 & 1.093 & 0.300 & 0.018 \\
\hline & Error (time.k) & 138.733 & 58 & 2.392 & & & \\
\hline & Group & 3.267 & 1 & 3.267 & 1.814 & 0.183 & 0.030 \\
\hline & Error & 104.467 & 58 & 1.801 & & & \\
\hline \multirow[t]{5}{*}{ Pulmonary capacity } & time.k & 34.341 & 1 & 34.341 & 4.599 & 0.036 & 0.073 \\
\hline & $\begin{array}{c}\text { time.k * } \\
\text { Group }\end{array}$ & .301 & 1 & .301 & 0.040 & 0.842 & 0.001 \\
\hline & Error (time.k) & 433.108 & 58 & 7.467 & & & \\
\hline & Group & 18.704 & 1 & 18.704 & 3.359 & 0.072 & 0.055 \\
\hline & Error & 322.942 & 58 & 5.568 & & & \\
\hline
\end{tabular}

$(\mathrm{p}<0.05)$ (Table 3). In this way, there was a significant difference between the two groups at different times. Based on the Bonferoni follow-up test, there was a significant difference between times 1 and 3 and 4 in the level of consciousness in the intervention group and also time two with time 3 and $4(\mathrm{p}<0.05)$. But in the control group, there was no significant difference between the times $(\mathrm{p}>0.05)$. In respiratory index $\left(\mathrm{PAO}_{2} / \mathrm{FIO}_{2}\right)$ in the intervention group, there was a significant difference between times 1 and 3 and 4 and time 2 with $4(\mathrm{p}<0.05)$.

There was no significant difference between the ICU length of stay of the two groups $(p>0.05)$. There was no significant difference between the required duration of mechanical ventilation of patients in the two groups $(p>0.05)$. There was no significant difference between the mortality rates of the two groups $(p>0.05)$ (Table 4$)$. 
Table 4. Comparison of ICU length of stay and required duration of mechanical ventilation and mortality rate of patients in intervention and control group

\begin{tabular}{lcc}
\hline Variable & Group & Control \\
\cline { 2 - 3 } & Intervention & $13.63 \pm 9.21$ \\
ICU length of stay (day) & $14.7 \pm 9.38$ & $12.26 \pm 5.39$ \\
duration of mechanical ventilation (day) & $10.66 \pm 3.55$ & 0.533 \\
Mortality & $29(96.7 \%)$ & $28(93.3 \%)$ \\
Yes & $1(3.3 \%)$ & $2(6.7 \%)$ \\
No & 0.276 \\
\hline
\end{tabular}

\section{Discussion}

According to the results, there was no potential dissimilarity between the mechanically ventilated patients admitted to the ICU in the two groups regarding age and gender. Therefore, it can be said that the two groups were similar in the case of age and sex and these variables cannot affect other factors as confounders.

Regarding the most important outcomes of this research, there was no potential difference among the mean arterial blood pressure, heart rate, respiration rate, oxygen saturation, APACHE II score, and pulmonary capacity of patients in the two groups on the first, second, third, and fourth days after the intervention. Moreover, the level of consciousness (according to GCS), respiratory index $\left(\mathrm{PAO}_{2} / \mathrm{FIO}_{2}\right)$, and PEEP level of the two groups did not have a significant difference within 1-2 days after the intervention.

Furthermore, it was found that the level of consciousness (according to GCS criteria), respiratory index $\left(\mathrm{PAO}_{2} / \mathrm{FIO}_{2}\right)$, and PEEP level of patients in the two groups did not experience any significant changes within 3 to 4 days after the intervention. In addition, there was no significant difference between the ICU length of stay, the required duration of mechanical ventilation, and the mortality rate of patients in the two groups. Therefore, NAC seems to have a positive effect on the treatment of ARDS in mechanically ventilated patients admitted to the ICU.

Based on the review of the related literature, few studies have been performed about the effect of NAC on the treatment of ARDS in mechanically ventilated patients admitted to the ICU. In a review study conducted by Lou et al. (2019), it was found that there was no potential modification in the mortality rate of individuals with ARDS who consumed acetylcysteine and the control group, which is consistent with the results of the present study. Nevertheless, in the above-mentioned study, the improvement of clinical conditions and $\mathrm{PaO} 2 / \mathrm{FiO} 2$ ratio was significantly better in the group that received NAC compared to the control group. They concluded that NAC does not affect the mortality rate; however, its use is beneficial in the improvement of the pulmonary conditions of patients in the ICU. Notwithstanding, the documented results that confirm the effectiveness of NAC for ARDS are limited, and there is a need for further research (17).

Based on the findings of another review study carried out by Young et al. (2017), NAC did not affect the reduction of the mortality rate of ARDS in adults. In addition, they found that the patients who received NAC were hospitalized for a longer time in the ICU, compared to the control group. Moreover, they observed a significant dif- ference between the intervention and control groups in terms of the respiratory index. Results of the aforementioned study indicated the effect of consumption of NAC on the improvement of the clinical condition of ARDS patients, which is in line with the findings of the present research (5).

Kevin et al. (2017), in their study, found that the respiratory index of ARSD patients secondary to inhalation injury in the NAC group significantly improved on the fourth day. They stated that the use of NAC in the treatment of inflammatory and oxidative conditions of the lung after injury would be very helpful (18). Their findings are consistent with those of the present study.

Najafi et al. (2017), in their research performed on neonates with ARDS admitted to the ICU, found that there was no significant difference between the NAC and control groups in terms of mortality rate and the need for mechanical ventilation. However, they reported that ARDS significantly improved in the group that received NAC, which is consistent with the findings of this study (19). According to the results of a meta-analysis conducted by Guala et al. (2011), which were in line with those of the present study, NAC had a positive effect on the improvement of the clinical condition of ARDS patients, including the reduction of the length of hospital stay, mortality, and required duration of mechanical ventilation. Moreover, they found that NAC can be useful as an antioxidant to prevent oxidative damage and improve the clinical condition in ARDS patients (20).

According to the results of a study carried out by Moradi et al. (2009), which were consistent with those of the present study, there was an improvement in respiratory index status $\left(\mathrm{PAO}_{2} / \mathrm{FIO}_{2}\right.$ ratio) and a reduction in the mortality rate of the NAC group, compared to the control group. They stated that the use of NAC affected the improvement of the clinical condition of ARDS patients; however, the evaluation and determination of the exact dose of this medication for the improvement of the pulmonary condition of ARDS patients require a study with a larger sample size (3).

\section{Study limitations}

One of the strengths of this study was its quasiexperimental design and the use of a control group. However, this study also had some limitations; for example, few similar studies have been performed, which limits the possibility of comparing the present research with other studies. Therefore, it is suggested that more similar studies be designed and carried out in the future. In addition, the sample size of the present study was small which could be 
the reason for the lack of a significant difference between the two groups. Therefore, it is suggested that future studies be performed on larger sample sizes.

\section{Conclusion}

Based on the results, it seems that NAC is an effective medication with low side effects for the treatment of ARDS in mechanically ventilated patients admitted to the ICU. It is suggested that the side-effects and dose changes of NAC be investigated in patients admitted to ICU in future studies.

\section{Acknowledgment}

The authors of this article would like to appreciate all the subjects who participated in this project.

\section{Conflict of Interests}

The authors declare that they have no competing interests.

1

\section{References}

1. Green JL, Heard KJ, Reynolds KM, Albert D. Oral and Intravenous Acetylcysteine for Treatment of Acetaminophen Toxicity: A Systematic Review and Meta-analysis. West J Emerge Med. 2013;14(3): 218-26.

2. Sanguinetti CM. N-acetylcysteine in COPD: why, how, and when?. Multidiscip Respir Med. 2015;11(1):1-1.

3. Moradi M, Mojtahedzade M, Mandegari A. The role of glutathione-stransferase polymorphisms on clinical outcome of ALI/ARDS patient treated with N-Acetylcycteine. Respir Med. 2009;103(3):434-44.

4. Ranieri VM, Rubenfeld GD, Thompson BT, Ferguson ND, Caldwell E, Fan E, et al. Acute respiratory distress syndrome: The Berlin definition. Jama. 2012;307(23):2526-2533.

5. Zhang Y, Ding S, Li C. Effects of $\mathrm{N}$-acetylcysteine treatment in acute respiratory distress syndrome: A meta-analysis. Exp Ther Med. 2017;14(4):2863-2868.

6. Herridge MS, Tansey CM, Matté A, Tomlinson G, Diaz-Granados N, Cooper A, et al. Functional disability 5 years after acute respiratory distress syndrome. N Engl J Med. 2011;364(14): 1293-1304.

7. Neamu RF, Martin GS. Fluid management in acute respiratory distress syndrome. Curr Opin Crit Care. 2013;19(1):24-30.

8. Piquilloud L, Tassaux D, Bialais E, Lambermont B, Sottiaux T, Roeseler J, et al. Neurally adjusted ventilatory assist (NAVA) improves patient-ventilator interaction during non-invasive ventilation delivered by face mask. Intensive Care Med. 2012;38(10):1624-1631.

9. Antonelli M, Conti G, Esquinas A, Montini L, Maggiore SM, Bello G, et al. A multiple-center survey on the use in clinical practice of noninvasive ventilation as a first-line intervention for acute respiratory distress syndrome. Crit Care Med. 2007;35(1):18-25.

10. Sinha P, Flower O, Soni N. Deadspace ventilation: A waste of breath! Intensive Care Med. 2011;37(5):735-746.

11. Chen W, Chen YY, Tsai CF, Chen SC, Lin MS, Ware LB, et al. Incidence and outcomes of acute respiratory distress syndrome: A nationwide registry-based study in Taiwan, 1997 to 2011. Medicine (Baltimore).2015;94(43):e1849.

12. Sagul AS, Fargo M. Acute Respiratory Distress Syndrome:Diagnosis and Management. Am Fam Physician. 2020;101(12):330-8

13. Pournajafian AR, Ghodraty MR, Faiz SHR, Rahimzadeh P, Goodarzynejad H, Dogmehchi E. Comparing glidescope video laryngoscope and macintosh laryngoscope regarding hemodynamic responses during orotracheal intubation: A randomized controlled trial. Iran Red Crescent Med J. 2014;16(4):e1233.

14. Gattinoni L, Quinte M. How ARDS should be treated. Critic Care. 2016;20(1):86

15. Nasajiyan N, Javaherfourosh F. Comparison of low and standard pressure gas injection at abdominal cavity on postoperative nausea and vomiting in laparoscopic cholecystectomy. Pakistan J Med Sci. 2014;30(5):1083.

16. Javaherforoosh Zadeh F, Moadeli M, Soltanzadeh M, Janatmakan F.
Effect of remote ischemic preconditioning on troponin I in CABG. Anesthesiol Pain Med. 2017;7(4):e12549.

17. Lu X, Ma Y, He J, Li Y, Zhu H, Yu X. N-acetylcysteine for adults with acute respiratory distress syndrome: A meta-analysis of randomized controlled trials. Hong Kong J Emerg Med. 2019;26(5):288-298.

18. Kevin M, Kristen L. Use of Nebulized Heparin, Nebulized NAcetylcysteine, and Nebulized Epoprostenol in a Patient with Smoke Inhalational Injury and Acute Respiratory Distress Syndrome. J Pharm Pract. 2017;30(6):663-667

19. Najafian B, Khosravi MH, Setayesh F. Comparing the Effect of Inhaler N-Acetyl Cysteine and Intravenous Dexamethasone on Respiratory Distress Syndrome in Premature Infants: A Randomized Clinical Trial. Thrita. 2011;6(1):e46268

20. Galvao AM, Andrade AD, Maia MBS. Antioxidant supplementation for the treatment of acute lung injury:a-meta-analysis. Rev Bras Ter Intensiva. 2011;23(1):41-48. 